\title{
Activation of the NLRP3 Inflammasome Pathway by Prokineticin 2 in Testicular Macrophages of Uropathogenic Escherichia coli- Induced Orchitis
}

\author{
Ying $\mathrm{Li}^{1,2}$, Yufang Su${ }^{1}$, Ting Zhou ${ }^{3}$, Zhiyong $\mathrm{Hu}^{1}$, Jiajing Wei ${ }^{1}$, Wei Wang ${ }^{1}$, Chunyan Liu ${ }^{1}$, \\ Huiping Zhang ${ }^{1 *}$ and Kai Zhao ${ }^{1 *}$ \\ ${ }^{1}$ Family Planning Research Institute/Reproductive Medicine Center, Tongji Medical College, Huazhong University of Science \\ and Technology, Wuhan, China, ${ }^{2}$ Prenatal Diagnostic Center, People's Hospital of Guangxi Zhuang Autonomous Region, \\ Nanning, China, ${ }^{3}$ Department of Gynecology and Obstetrics, Union Hospital, Tongji Medical College, Huangzhong University \\ of Science and Technology, Wuhan, China
}

OPEN ACCESS

Edited by:

Thomas A. Kufer,

University of Hohenheim, Germany

Reviewed by:

Joseph Alex Duncan,

University of North Carolina at Chape

Hill, United States

Andreas Meinhardt,

University of Giessen, Germany

*Correspondence:

Huiping Zhang

zhpmed@126.com

Kai Zhao

kai_zhao@hust.edu.cn

Specialty section

This article was submitted to

Molecular Innate Immunity,

a section of the journal

Frontiers in Immunology

Received: 26 March 2019

Accepted: 24 July 2019

Published: 14 August 2019

Citation:

Li Y, Su Y, Zhou T, Hu Z, Wei J, Wang W, Liu C, Zhang $H$ and Zhao $K$

(2019) Activation of the NLRP3

Inflammasome Pathway by

Prokineticin 2 in Testicular Macrophages of Uropathogenic Escherichia coli- Induced Orchitis. Front. Immunol. 10:1872. doi: 10.3389/fimmu.2019.01872
Infections of the reproductive tract are known to contribute to testicular inflammatory impairment, leading to an increase of pro-inflammatory cytokines such as IL-1 $\beta$, and a decline in sperm quality. Prokineticin 2 (PK2), a secretory protein, is closely associated with the secretion of pro-inflammatory cytokines in inflamed tissue. It was reported that increased PK2 is related to the upregulation of IL-1 $\beta$, but the underlying mechanism remains elusive. Here, we illustrated that PK2 was upregulated in testicular macrophages (TM) in a rat model of uropathogenic Escherichia coli (UPEC) infection, which induced the activation of the NLRP3 inflammasome pathway to boost IL-1 $\beta$ secretion. Administration of PK2 inhibitor alleviated the inflammatory damage and suppressed IL-1 $\beta$ secretion. Moreover, PK2 promoted NLRP3 expression and the release of cleaved IL-1 $\beta$ from TM to the supernatants after the challenge with UPEC in vitro. IL-1 $\beta$ in the supernatants affected Leydig cells by suppressing the expression of genes encoding for the enzymes P450scc and P450c17, which are involved in testosterone production. Overall, we revealed that increased PK2 levels in TM in UPEC-induced orchitis may impair testosterone synthesis via the activation of the NLRP3 pathway. Our study provides a new insight into the mechanisms underlying inflammation-associated male infertility and suggests an anti-inflammatory therapeutic target for male infertility.

Keywords: Prokineticin 2, IL-1 $\beta$, testicular macrophages, inflammasome, orchitis

\section{INTRODUCTION}

The declining in sperm quality and male infertility constitute an international concern in recent years, and infections of the reproductive tract are known to contribute to $\sim 15 \%$ of male infertility cases. Uropathogenic Escherichia coli (UPEC) is estimated to be the predominant etiological agent of genitourinary infections, which can be isolated from urine and semen samples of 50 to $95 \%$ of patients $(1,2)$. Several investigations have proposed that the testicular impairment in an infectious process is caused by the host's immune reaction rather than by direct cytotoxic damage from the 
pathogen (3). Therefore, research into the immune regulation of inflammation-associated male infertility is of great significance to clinical diagnosis and treatment.

The testicular macrophages (TM) serve as the largest proportion of immune cells in the testicular interstitial space, constituting the first line of defense against pathogens. Rat TM are comprised of two distinct populations: $\mathrm{CD} 8^{+}$. $\mathrm{CD}_{163}{ }^{-}$(inflammatory-activated state) and $\mathrm{CD}^{+} 8^{+} \mathrm{CD}_{163}{ }^{+}$ (immunosuppressive state), and TM primarily present immunosuppressive characteristics compared with other macrophages (4). When TM were challenged with UPEC, the deficiency of I $\mathrm{B} \alpha$ degradation indicated that the NF- $\kappa \mathrm{B}$ pathway was blocked, however, the phosphorylation of mitogen-activated protein (MAP) kinases was induced. Opposite results were apparent in peritoneal macrophages (5). The transcription of pro-inflammatory genes, such as interleukin-1 $\beta$ (IL-1 $\beta$ ), may be triggered by MAPK activation, and IL- $1 \beta$ mRNA was increased in TM after UPEC infection (6).

Several studies have suggested that macrophages and IL-1 $\beta$ are involved in the initiation and progress of orchitis (7). IL$1 \beta$ production and release occurs in two stages. It is generally recognized that NF- $\kappa \mathrm{B}$ activation is the first step in evoking the synthesis of pro-IL-1 $\beta$. Certain investigations suggested that MAPKs are also involved in this process (8). The second step is the inflammasome assembly, which is composed of a cytoplasmic sensor molecule, such as PYD domain-containing protein 3 (NLRP3), the adaptor protein [apoptosis-associated speck-like protein containing caspase recruitment domain (ASC)], and the effecter protein (pro-caspase-1). NLRP3 and ASC facilitate pro-caspase-1 cleavage to form the active complex, which triggers pro-IL- $1 \beta$ cleavage into the mature IL-1 $\beta$ (9). In the testis, crosstalk between Toll-like receptors and NOD-like receptors converge in the activation of the NF- $\kappa \mathrm{B}$ and NLRP3 pathways, leading to IL-1 $\beta$ secretion from Sertoli cells (10). Moreover, NLRP3, ASC, caspase-1, and IL-1 $\beta$ were shown to be significantly elevated in somatic non-immune cells (Sertoli cells and peritubular cells) in a mouse model of infertility characterized by inflammation and impaired spermatogenesis (11). However, until now, no studies have concentrated on the role of NLRP3 in TM.

Prokineticin 2 (PK2), a small secretory protein, binds with its specific receptors, to mediate signal transduction to promote an inflammatory response. PK2 is expressed in peripheral blood mononuclear cells and abundantly expressed in infiltrating neutrophils and macrophages in inflamed tissues, recruiting infiltrated leukocytes during the inflammatory process $(12,13)$. PK2 is a central player that participates in psoriasis by promoting IL- $1 \beta$ expression in keratinocytes and macrophages to induce inflammatory cascades and the hyperproliferation of keratinocytes (14). Furthermore, PK2 was shown to promote lipopolysaccharides (LPS)-induced IL-1 $\beta$ production in peritoneal macrophages in vitro (15). However, the complete mechanism is unclear.

Considering the potential relationship between PK2 and IL$1 \beta$, we inferred that PK2 is closely associated with the regulation of the inflammatory process during UPEC-induced orchitis. The present study focused on determining the effect of PK2 on
IL-1 $\beta$ secretion in TM during UPEC infection and uncovering the underlying molecular mechanisms which, ultimately, impair male fertility.

\section{MATERIALS AND METHODS}

\section{Animals}

Adult male Wistar rats (8-10 weeks of age) were purchased from the Animal Center of Tongji Medical College. The animals were kept at $22^{\circ} \mathrm{C}$ with a $12 \mathrm{~h}$ light/dark cycle and fed with standard food pellets and water ad libitum. This study was performed in strict accordance with the approved guidelines from the Institutional Animal Care and Use Committee of Tongji Medical College, Huazhong University of Science and Technology (NO.2018_S808).

\section{PROPAGATION OF BACTERIA}

The UPEC strain CFT073 (NCBI: AE014075, NC_004431) characterized by Welch et al. was used (16). CFT073 fresh cultures were shaken in LB medium and grown to the early exponential phase $(\mathrm{OD} 600=0.5-1.0)$. The bacterial cultures were centrifuged at $4,500 \times \mathrm{g}$ for $8 \mathrm{~min}$ at room temperature. The pellets were washed with PBS and stored in DMEM/F12. A multiplicity of infection (MOI) of 20 was applied and confirmed by calculating the colony-forming units after serial dilution.

\section{Animal Treatment}

UPEC-induced experimental orchitis was elicited in male Wistar rats as previously described (17). Under general anesthesia, the testes, epididymis, and vas deferens were exposed. Approximately $4 \times 10^{6}$ bacterial cells in $50 \mu \mathrm{L}$ of a UPEC saline suspension were injected into the vas deferens proximal to the cauda epididymis. Sham operated rats were injected with the same volume of saline. A ligation was made at the injection site to prevent the infection from spreading. PKR-A[(3R)-1-(4-Fluoro-3-methoxybenzyl)$\mathrm{N}$-(9-chloro-3,4-dihydro-2H-1,5-benzodioxepin-7-ylmethyl)$\mathrm{N}$-isobutylpyrrolidine-3-carboxamide)] was kindly donated by Prof. Qunyong Zhou (University of California, Irvine, USA). PKR-A was dissolved in DMSO (Sigma, USA) and diluted with PBS to adjust the concentration of DMSO to $5 \%$. On day 1 post-infection, the UPEC-infected rats were injected with either $20 \mathrm{mg} / \mathrm{kg}$ of PKR-A or 5\% DMSO into the testes every 2 days during the experiment. The sham operated rats received $5 \%$ DMSO and the rats were treated with PKR-A alone as a control.

\section{Sample Collection}

The animals were sacrificed on day 7 post-operation. For the histopathological assessment, the testes were removed and fixed with Bouin's fluid to prepare paraffin sections to be stained with hematoxylin and eosin. To collect the testicular interstitial fluid, a small incision was made in the distal end of the testicular capsule, avoiding injury of the seminiferous tubule. Subsequently, testes were suspended in a tube at $4^{\circ} \mathrm{C}$ overnight. After centrifugation, the cellular contaminants were discarded. 


\section{Sperm Preparation and Analysis}

The epididymis was removed and incised into small pieces in Hams F10 medium and incubated at $37^{\circ} \mathrm{C}$ for $30 \mathrm{~min}$ to allow the spermatozoa to swim out. A drop of sperm sample was placed on a slide, and 200 spermatozoa were analyzed using light microscopy according to the criteria of the World Health Organization manual (18). Sperms of Grade A (fast progressive) and Grade B (slow progressive) were identified as progressive motility.

\section{Testicular Histopathology}

The testes were immersed in Bouin's fluid at $4^{\circ} \mathrm{C}$ overnight and then embedded in paraffin. Then, the continuous paraffin sections were dewaxed with xylene and stained with hematoxylin-eosin (H\&E) to detect testicular histopathology.

\section{Cell Isolation}

Testicular macrophages and Leydig cells were isolated from adult male Wistar rats $(6,19)$. The animals were sacrificed by isofluran inhalation. The testes were decapsulated and digested with 1 $\mathrm{mg} / \mathrm{mL}$ collagenase I (Sigma, USA) at $34^{\circ} \mathrm{C}$ for $15 \mathrm{~min}$. After the digestion was terminated, the product was filtered to separate the interstitial cells, and seminiferous tubules.

After centrifugation and resuspension, the interstitial cells were cultured with DMEM/F12 (Life Technologies, USA). After $1 \mathrm{~h}$, the non-adherent cells were removed by rinsing with the medium. The adherent interstitial cells comprised primarily macrophages, estimated at 80 to $90 \%$ by flow cytometryusing the mouse anti-CD68 monoclonal antibody (Bio-Rad, USA).

For the isolation of Leydig cells, the interstitial cells were centrifuged, resuspended, and then purified on a discontinuous four-layer Percoll (GE, USA) density gradient $(21,26,37$, and $60 \%)$. The gradient was centrifuged and the interphase between 37 and $60 \%$ was collected. The purity of Leydig cells was determined by a positive cytochemical reaction for $3 \beta$-HSD (Sigma, USA). Purity of TM and LC was $80-90 \%$.

\section{Cell Treatments}

For the infection of the cells, TM were primed with $1 \mu \mathrm{g} / \mathrm{mL}$ LPS (Sigma, USA) for $4 \mathrm{~h}$ or untreated, and then infected with UPEC $(\mathrm{MOI}=20)$ with or without PK2 (Peprotech, USA) for $2 \mathrm{~h}$. In the inhibitory experiments, LPS-primed TM were pretreated with NLRP3 inhibitor MCC950 (10 $\mu \mathrm{M}$, Selleck Chemicals, USA) or caspase-1 inhibitor VX-765 (50 $\mu \mathrm{M}$, Selleck Chemicals, USA) for $1 \mathrm{~h}$, and then infected with UPEC (MOI $=20)$ with or without PK2 for $2 \mathrm{~h}$.

For the detection of caspase- 1 activity, TM were not pretreated with LPS. TM were treated with UPEC for $2 \mathrm{~h}$ in the presence or absence of PK2 and PKR-A $(0.8 \mu \mathrm{M})$.

To disrupt testosterone production, recombinant IL$1 \beta$ protein (R\&D Systems, USA) was added at various concentrations $(1,10,100 \mathrm{nM})$ to the conditioned medium in which Leydig cells were growing for $24 \mathrm{~h}$. Moreover, the conditioned medium from TM with various treatments was collected and filtered and then co-cultured with Leydig cells
TABLE 1 | Real-time PCR primer sequences

\begin{tabular}{|c|c|c|}
\hline Gene & Primer sequence & Length (bp) \\
\hline \multirow[t]{2}{*}{ PK2 } & FP:5'-CAAGGACTCTCAGTGTGGA-3' & 128 \\
\hline & RP:5'-AAAATGGAACTITCCGAGTC-3' & \\
\hline \multirow[t]{2}{*}{ StAR } & FP:5' -CGTGGCTGCTCAGTATTGACCTC-3' & 95 \\
\hline & RP:5'-CAAGTGGCTGGCGAACTCTATCTG-3' & \\
\hline \multirow[t]{2}{*}{ P450scc } & FP:5' -CCGGCGGATTGCAGAACTGG-3' & 156 \\
\hline & RP:5'-TGCTTGAGAGGCTGGAAGTTGAAG-3' & \\
\hline \multirow[t]{2}{*}{ P450c17 } & FP:5' -GGACCAGCCAGATCAGTTCATGC-3' & 164 \\
\hline & RP:5' -GCAGTAGCAAGGCCGTGAAGAC-3' & \\
\hline \multirow[t]{2}{*}{$17 \beta-\mathrm{HSD}$} & FP:5' -AGCGGTTGTGGAGAAGTAGC-3' & 114 \\
\hline & RP:5'-GTGGTTATGAGCAAGCCCTGAG-3' & \\
\hline \multirow[t]{2}{*}{$3 \beta-H S D$} & FP:5' -ACCGCTGCTGTCATTGATGTCTC-3' & 123 \\
\hline & RP:5'-GTAGATGAAGGCTGGCACACTGG-3' & \\
\hline \multirow[t]{2}{*}{$\beta$-actin } & FP:5'-GAGAGGGAAATCGTGCGT-3’ & 93 \\
\hline & RP:5'-GGAGGAAGAGGATGCGG-3' & \\
\hline
\end{tabular}

for $24 \mathrm{~h}$. The control group included Leydig cells were treated with TM culture supernatant which are not treated with LPS and UPEC etc. The anti-IL- $1 \beta$ antibody $(10 \mu \mathrm{g} / \mathrm{mL})$ was used to block IL- $1 \beta$ activity.

\section{Real-Time RT-PCR}

Total RNA was isolated from the TM using TRIzol reagent (Invitrogen, USA). The reverse transcription was performed using the PrimeScript ${ }^{\mathrm{TM}}$ RT reagent Kit (Takara, Japan). PCR was performed in a $20 \mu \mathrm{L}$ reaction mixture including $2 \mu \mathrm{L}$ of cDNA, $0.8 \mu \mathrm{L}$ of the forward primers and $0.8 \mu \mathrm{L}$ of reverse primers (Table 1), and $10 \mu \mathrm{L}$ of SYBR Green PCR MasterMix (Takara, Japan). Relative expression levels of the target genes were normalized with those of the controls using the $2^{-\Delta \Delta \mathrm{Ct}}$ method.

\section{Western Blot}

The supernatants were added to 4 times the volume of pre-cooled acetone, incubated at $-20^{\circ} \mathrm{C}$ overnight, and then centrifuged at $10,000 \mathrm{rpm}$ for $10 \mathrm{~min}$. The precipitate was washed with pre-cooled acetone to acquire the concentrated supernatants. The concentrated supernatants and cells were lysed on ice with RIPA buffer. Subsequently, 20 to $40 \mu \mathrm{g}$ of protein were electrophoresed on an 8 to $12 \%$ sodium dodecyl sulfate-polyacrylamide gel and transferred to a nitrocellulose membrane. The membranes were blocked with 5\% nonfat milk for $1 \mathrm{~h}$ in TBS and subsequently incubated with the following primary antibodies: goat anti-IL-1 $\beta$ polyclonal antibody (1:1,000, R\&D Systems, USA), rabbit anti-NLRP3 polyclonal antibody (1:500, Novus, USA), mouse anti-caspase1 monoclonal antibody (1:500, Novus, USA), mouse anti- $\beta$ actin polyclonal antibody (1:500, Boster, China), and mouse anti-PK2 monoclonal antibody (1:2,000, donated by Prof. Qunyong Zhou). The protein bands were detected using ECL (Pierce, USA). 


\section{ELISA}

The levels of PK2 and IL-1 $\beta$ in the testicular interstitial fluid and cell supernatants were quantified using specific sandwich ELISA following the manufacturer's instructions. PK2 was measured using an ELISA Kit from CUSABIO (China). IL- $1 \beta$ levels were evaluated using an ELISA Kit from R\&D Systems (USA).

\section{Immunofluorescence}

Cells seeded in a cover glass were washed with PBS and then fixed with pre-cooled $4 \%$ formaldehyde. Subsequently, the cells were blocked with $5 \%$ normal goat serum at room temperature for $1 \mathrm{~h}$ and then incubated with the rabbit antiPK2 polyclonal antibody (1:200, Abcam, USA) and mouse antiCD68 monoclonal antibody (1:200, Abcam, USA) overnight. After washing twice with PBS, the cells were incubated with the appropriate secondary antibodies: donkey anti-mouse IgG H\&L (Alexa Fluor ${ }^{\circledR}$ 647) $(1: 500$, Abcam, USA) and goat anti-rabbit IgG H\&L (FITC) (1:500, Abcam, USA) at room temperature for $1 \mathrm{~h}$. The cell nuclei were stained with DAPI (biofroxx, Germany).

\section{Flow Cytometric Analysis}

For the flow cytometric analyses, $350 \mu \mathrm{L}$ of interstitial single-cell suspensions (approximately $1 \times 10^{6}$ cells) were incubated with 2 $\mu \mathrm{L}$ of mouse anti-CD45-PE/Cy7 (BioLegend, USA) and $2 \mu \mathrm{L}$ of mouse anti-CD163-Alexa Fluor 647 monoclonal antibody (BioRad, USA). After centrifugation, the pellets were resuspended and incubated in fixation/permeabilization solution (BD, USA). Subsequently, the cells were incubated with $2 \mu \mathrm{L}$ of mouse anti-CD68-Alexa Fluor 488 (Bio-Rad, USA). After excluding cell aggregates and doublets based on side scatter A (SSC-A) vs. SSC-H plot, $\mathrm{CD}^{2} 5^{+}$cells were analyzed to identify the testicular macrophage population by CD68 and CD163. Flow cytometry analysis was performed by using a flow cytometer (BD LSR II, USA), and data were analyzed with FlowJo software version X.

\section{Caspase-1 Activity Assay}

A Caspase-1 Activity Kit (BioVision, Mountain View, CA, USA) was used to evaluate caspase-1 activity. The yellow formazan product $\mathrm{p}$-nitroaniline (pNA) was converted from the labeled substrate acetyl-Tyr-Val-Ala-Asp p-nitroanilide (AcYVAD- $p$ NA) by activated caspase-1. Cell lysates were incubated with $5 \mu \mathrm{L}$ of Ac-YVAD-pNA $(4 \mathrm{mM})$ at $37^{\circ} \mathrm{C}$ for $1 \mathrm{~h}$. The absorbance values of $p$ NA were detected at $405 \mathrm{~nm}$. The product of pNA reflected the activation of caspase-1.

\section{Testosterone Detection}

For the chemiluminescent immunoassay, the serum levels of testosterone were measured using a chemiluminescent immunoassay kit (Cloud clone, China) following the manufacturer's protocols. According to the standard curve of known concentrations, the testosterone level was extrapolated.

For the liquid chromatography-mass spectrometry (LCMS), $200 \mu \mathrm{L}$ sample was taken, and pre-cooled $800 \mu \mathrm{L}$ of methanol/acetonitrile (1:1) was added to precipitate the protein, then centrifuged at $14,000 \mathrm{~g}$ for $4 \mathrm{~min}$ at $4^{\circ} \mathrm{C}$. Then, the supernatants was taken and dried under vacuum. Then, $100 \mu \mathrm{L}$ acetonitrile-water (1:1) was added. Afterthat, the fluid was centrifuged at $14,000 \mathrm{~g}$ for $15 \mathrm{~min}$ at $4^{\circ} \mathrm{C}$. The treated supernatants was analyzed in liquid chromatograph LC-30A (SHIMADZU, Japan) and 4,500 QQQ mass spectrometer (AB Sciex, American).

\section{Statistical Analysis}

Statistical package for social science (SPSS) 18.0 and GraphPad Prism software 5.0 were used to conduct the statistical analyses. Data are presented as the mean \pm standard error of the mean (SEM). Differences between two groups were analyzed by an unpaired $t$-test. Intergroup differences in multiple groups were measured using one-way ANOVA with Tukey's HSD post hoc test. $P<0.05$ were considered significant.

\section{RESULTS}

\section{PK2 Is Upregulated in TM of UPEC-Induced Rat Orchitis}

To explore the role of PK2 in UPEC-induced orchitis, a rat model was established according to a previously described method (17). Seven days after the treatment, the testes exhibited characteristics including a smaller size, various degrees of swelling, and a softer texture compared with the control rats (Figure 1A). Given that the invasion and location of UPEC were detected in the testicular interstitium (17), we focused on TM, which are the most abundant immune cells in the testicular interstitium. PK2 mRNA expression was upregulated in TM isolated from the UPEC-infected rats (Figure 1B). In addition, PK2 protein level was obviously elevated in cell lysates, as well as in TM supernatants of the UPEC-infected group (Figure 1C, Supplementary Figures S1, S9). The level of PK2 in the supernatants of the UPEC-infected group was remarkably higher compared with the control group, according to the quantitative analysis (Figure 1D). The micro-environmental conditions were evaluated in the interstitial fluid surrounding the TM, and the protein level of PK2 in the interstitial fluid was measured by ELISA. The expression of PK2 was not found in normal interstitial fluid, whereas it was dramatically increased in the UPEC-infected group (Figure 1E). Next, the capacity of UPEC to trigger PK2 release in vitro was also determined. Normal TM secreted little PK2, while UPEC promoted the release of PK2 (Figure 1F). Subsequently, the location of PK2 in the TM was identified by the expression of the rat macrophage surface receptor marker CD68 in the different groups. PK2 was observed in the nucleus in the control group. However, UPEC infection induced PK2 to diffuse throughout the cytoplasm, indicating that secretory PK2 protein was engaged in an efficient production and release process (Figure 1G). In summary, TM were induced to express pro-inflammatory PK2 in UPEC-infected rats, which abundantly accumulated in the cytoplasm and was released into the extracellular fluid to a greater extent compared with the control.

\section{PKR-A Alleviates UPEC-Induced Testicular Inflammation}

Considering the pro-inflammatory role of PK2, its effects on the progression of the inflammatory response and male fertility were 
A

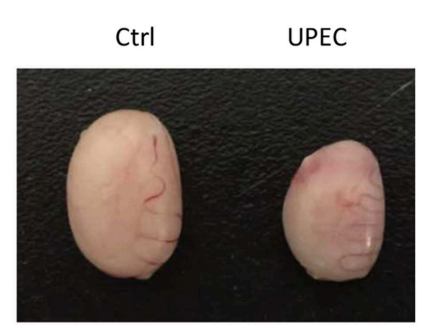

D

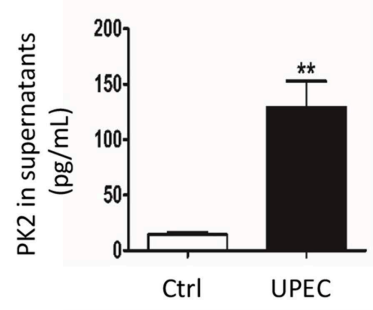

G

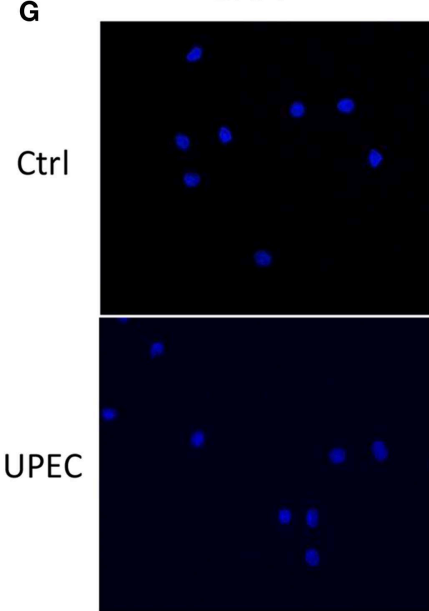

B

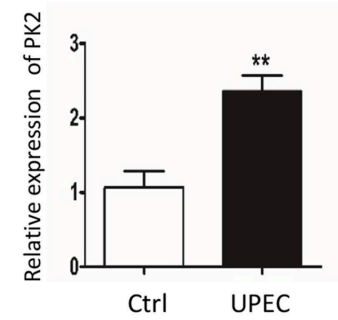

E

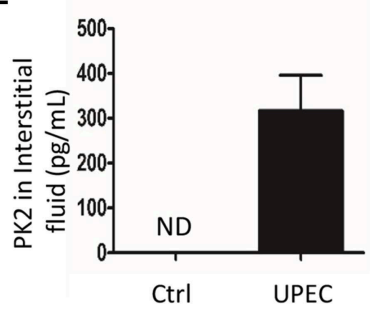

PK2
C
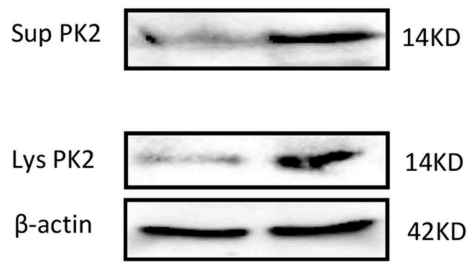

Ctrl UPEC

$\mathbf{F}$

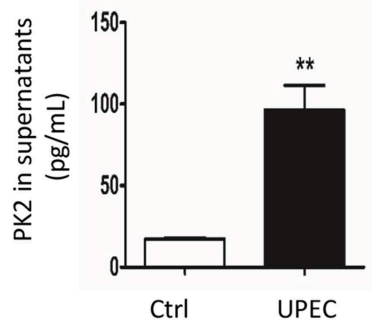

Merge
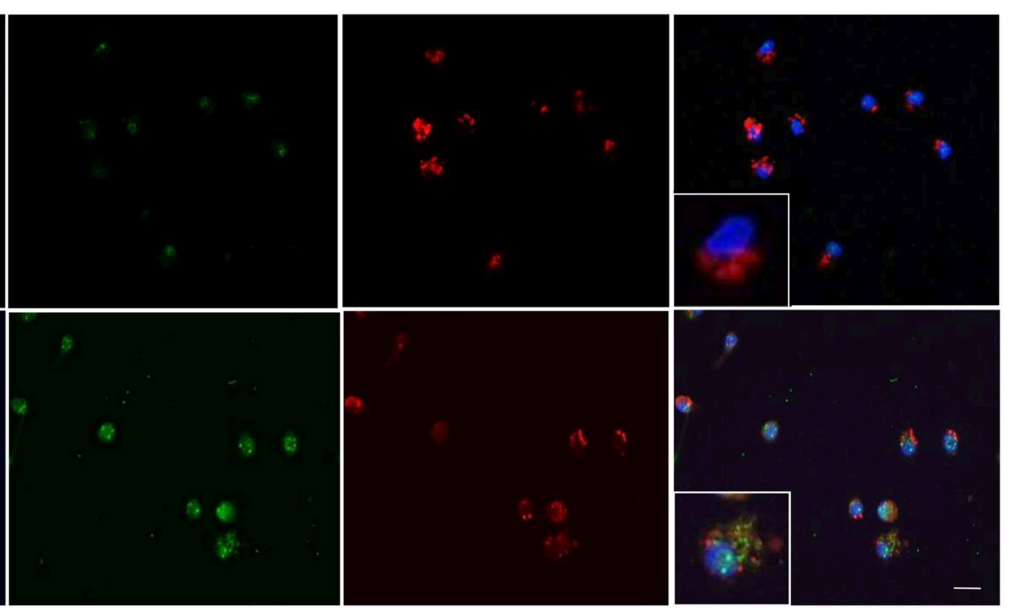

FIGURE 1 | PK2 is upregulated in TM in UPEC-induced orchitis. UPEC saline suspension was separately injected into the vas deferens proximal to the cauda epididymis, which reached the testis via a retrograde infection. Sham operated rats injected with the same volume of saline served as the control. (A) Testicular morphology, Ctrl (left) and UPEC (right) ( $n=5 /$ group). (B) PK2 mRNA expression in TM was detected by PCR ( $n=5 /$ group). (C) The cells were isolated from control and UPEC-treated rat testes, and then the medium was changed after the cells adhered to the wall for $1 \mathrm{~h}$. After a further culture for $2 \mathrm{~h}$, TM and the supernatants were collected. The protein level of PK2 in TM and the supernatant was analyzed by western blot. (D) The PK2 protein level in the supernatants of TM isolated from rats was analyzed by ELISA ( $n=5 /$ group). (E) The protein level of PK2 in the testicular interstitial fluid was determined by ELISA ( $n=5 /$ group). (F) TM were sham treated or UPEC infected (MOI, 20) for $2 \mathrm{~h}$ in vitro. PK2 level expression in the supernatants was determined by ELISA ( $n=5 / g r o u p)$. (G) TM were isolated from the rat testes of two groups. PK2 expression in TM was detected by immunofluorescence. Scale bar $50 \mu \mathrm{m}$. Ctrl, control; Lys, cell lysates, Sup, supernatants. ${ }^{\star *} P<0.01$ ( $t$-test).

investigated. PAR-A, an inhibitor of PK2, was administered via injection to UPEC-infected rat testes to suppress PK2 activity. After UPEC infection, inflammatory damage of testicular tissue and abnormal morphology of spermatogenic cells in tubules were observed. However, after PKR-A treatment, inflammation was alleviated, and the damage to germ cells damage was milder (Figure 2A). Furthermore, UPEC exerted a negative influence on total sperm count and forward motility, while the UPEC+PKR-A group exhibited a partial recovery of these factors (Figures 2B,C). In the UPEC-infected group, the proportion of $\mathrm{CD} 8^{+}{ }_{-} \mathrm{CD} 163^{+}$ macrophages with immunosuppressive effects was decreased compared to the control group. However, this change was reversed after PKR-A treatment (Figure 2D). UPEC reduced testosterone production in the serum, while the UPEC+PKR-A group exhibited a partial recovery (Figure 2E). The results of LC-MS further verified the trend of testosterone production in different treatment groups (Figure 2F). Taken together, our findings suggested that PK2 promoted inflammation in the testis, which impaired male reproduction, however, the PK2 antagonist PKR-A alleviated the inflammation and facilitated the recovery of sperm count, forward motility and testosterone production. The rats treated with PKR-A alone had no significant changes in testicular histomorphology and parameters related to male reproduction. 


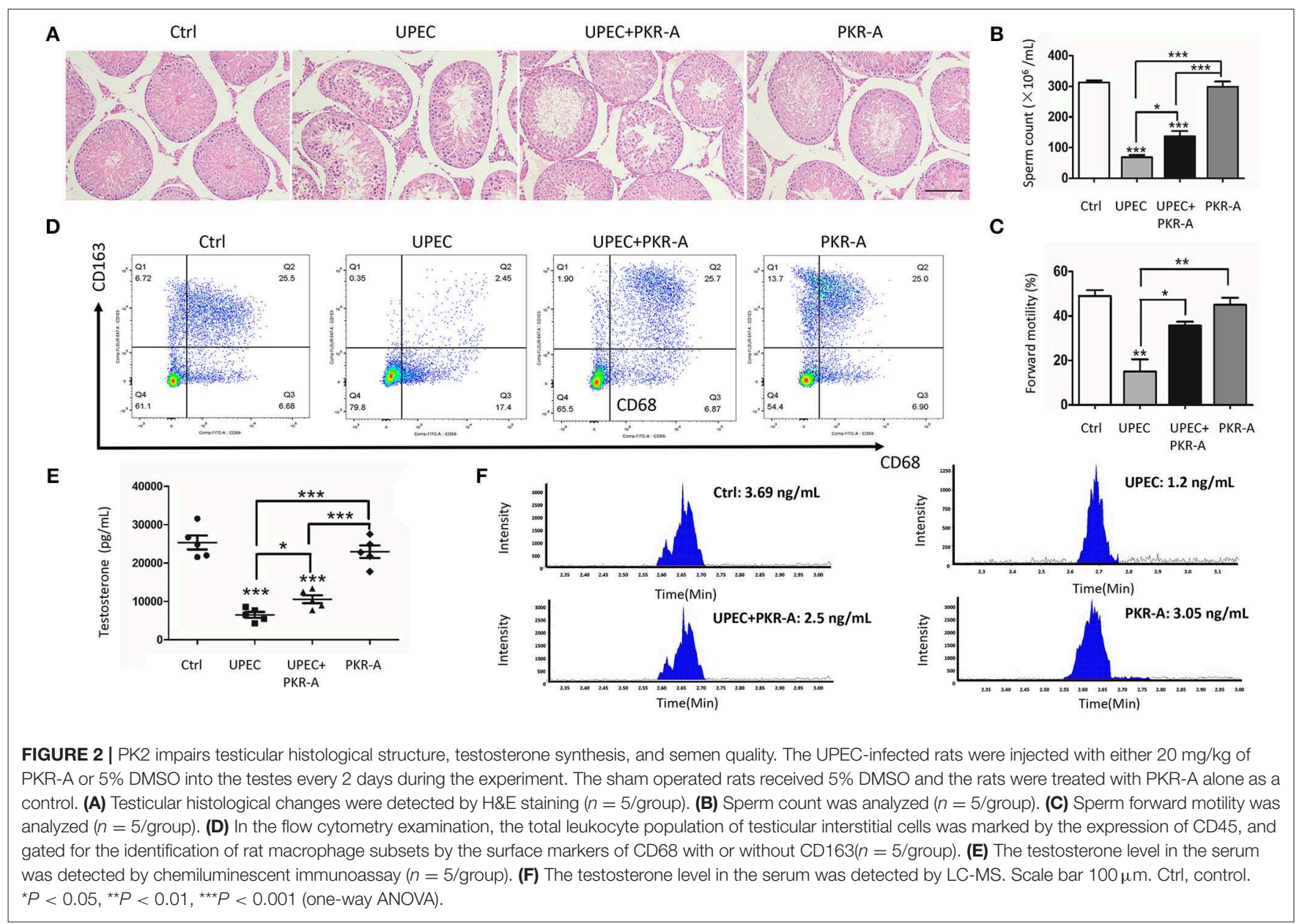

\section{Inhibition of PK2 Activity Decreases IL-1 $\beta$ Secretion}

To explore the potential involvement of PK2 in IL-1 $\beta$ secretion, IL- $1 \beta$-associated pathways were investigated. UPEC triggered robust IL- $1 \beta$ release into the interstitial fluid, however, this response was greatly reduced after PKR-A treatment (Figure 3A). IL-1 $\beta$ release is considered to be a marker for inflammasome activation, thus we further investigated other associated components of the inflammasome pathway. A similar trend was observed for cleaved caspase-1 activity: caspase-1 cleavage was elicited in TM from rats infected with UPEC, but this effect was weakened in the PKR-A-treated group (Figure 3B). To further clarify the specific mechanism of inflammasome activation, the different expression patterns of caspase- 1 and IL- $1 \beta$ in TM, and the supernatants were assessed by western blot. UPEC induced a significant increase of cleaved IL- $1 \beta$ and cleaved caspase- 1 release from the TM into the supernatants compared with the uninfected rats, but this release was decreased by PKR-A treatment. In TM, the protein level of NLRP3, cleaved caspase-1, and cleaved IL-1 $\beta$ were markedly increased in the UPEC-infected group, but this increase was attenuated in the UPEC+PKR-A group. UPEC promoted the cleavage of pro-IL-1 $\beta$ to form mature IL-1 $\beta$ to be released, thus the level of the pro-IL-1 $\beta$ protein was decreased in the infected group. Interestingly, after the PKR-A treatment, pro-IL$1 \beta$ expression remained at a high level in the TM (Figure 3C, Supplementary Figures S2-S6). Taken together, our findings suggested that the NLRP3 inflammasome pathway was activated in TM after UPEC infection in vivo, leading to the cleavage of pro-IL-1 $\beta$ to IL- $1 \beta$. In addition, PK2 was involved in the NLRP3 inflammasome activation.

\section{PK2 Promotes the Activation of the NLRP3 Inflammasome Pathway}

PK2 and its receptor follow the G-protein-coupled receptor signaling pattern, activate the PK2 transcription, release the functional PK2 protein from the cytoplasm to the extracellular milieu, and further activate this pathway (20). Given that UPEC directly triggered PK2 release, and the interstitial fluid contained a high concentration of PK2 in the UPEC-infected rats, ectogenic PK2 was applied to mimic the TM milieu to boost this positive feedback process to illuminate the effects of PK2 on the NLRP3 inflammasome pathway in vitro. Moreover, LPS pretreatment was administered to promote pro-IL-1 $\beta$ levels, facilitating the evaluation of IL-1 $\beta$ release as a hallmark for inflammasome activation with minimal interference by UPEC (21). It was 

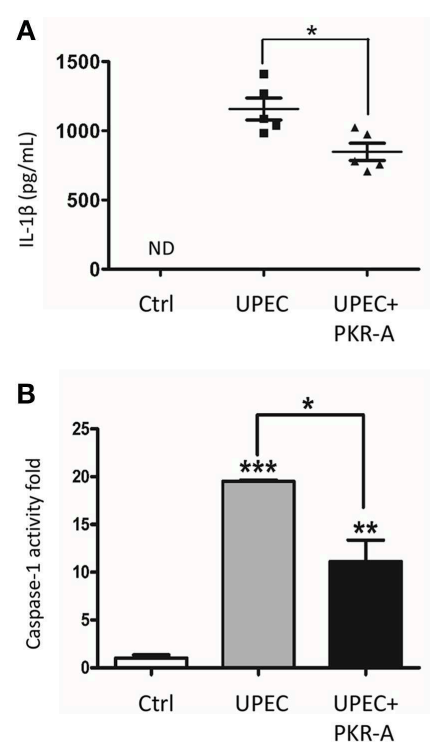

C
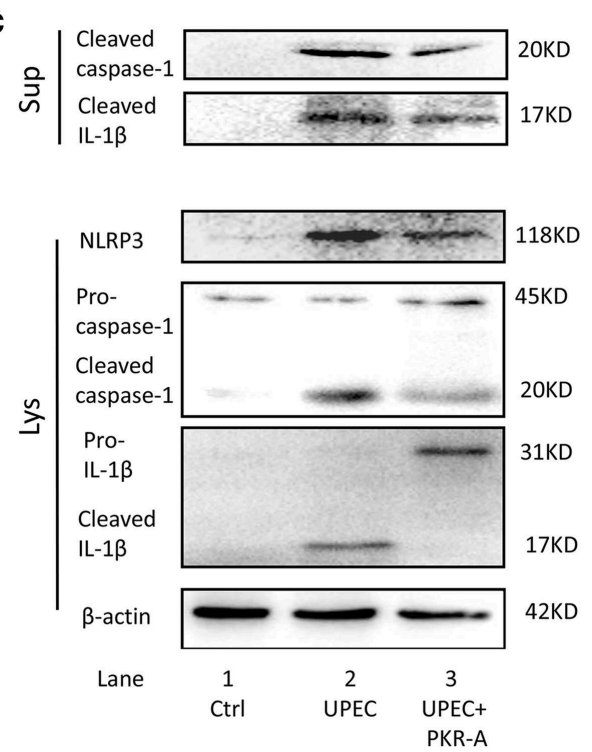

FIGURE 3 | Inhibition of PK2 results in decreased IL-1 $\beta$ secretion. The UPEC-infected rats were injected with either $20 \mathrm{mg} / \mathrm{kg}$ of PKR-A or $5 \%$ DMSO into the testes every 2 days during the experiment. The sham operated rats received 5\% DMSO as a control. TM were isolated from the three groups. The supernatants were collected after the isolated TM were further cultured for $2 \mathrm{~h}$. (A) IL-1 $\beta$ secretion of the testicular interstitial fluid was analyzed by ELISA ( $n=5 / \mathrm{group}$ ). (B) Whole-cell lysates were analyzed by caspase- 1 activity assay to determine the cleaved-caspase- 1 activity $(n=3 /$ group). (C) Concentrated supernatants were analyzed by western blot with antibodies against IL-1 $\beta$, caspase- 1 . Whole-cell lysates were analyzed by western blot with antibodies against IL-1 $\beta$, caspase-1, NLRP3, and $\beta$-actin. Ctrl, control; ND, no detected; Lys, cell lysates, Sup, supernatants. ${ }^{\star} P<0.05,{ }^{\star \star} P<0.01,{ }^{\star \star \star} P<0.001$ (one-way ANOVA).

found that IL- $1 \beta$ secretion in the supernatants was increased by UPEC with LPS priming. The additional PK2 induced IL-1 $\beta$ secretion in a dose-dependent manner (Figure 4A). As illustrated in the western blot results, cleaved IL-1 $\beta$ in the supernatants was higher in the UPEC with or without PK2 group compared to the control or LPS alone treatment group (Figure 4B, Supplementary Figures S6-S8). Correspondingly, a significant increase in cleaved caspase-1 activity occurred after UPEC infection, and higher cleaved caspae-1 production was further promoted by the additional PK2 (Figure 4C). Cleaved caspase-1 in the supernatants and NLRP3 expression in TM were strongly upregulated when the cells were challenged with UPEC with or without PK2, compared unstimulated cells (Figure 4D, Supplementary Figures S4, S7-S9). Taken together, these findings indicate that PK2 augments the effects of UPEC on the activation of the NLRP3 inflammasome pathway in vitro.

\section{PK2-Mediated IL-1 $\beta$ Secretion Is Dependent Upon the NLRP3 Pathway}

To further verify the involvement of the NLRP3 pathway in TM challenged by UPEC with or without PK2, MCC950 (NLRP3 inhibitor), and VX-765 (caspase-1 inhibitor) were used. In LPSprimed TM, MCC950, and VX-765 significantly suppressed the UPEC-induced IL- $1 \beta$ release in the supernatants, and additional PK2 did not reverse this trend (Figure 5A). Similarly, in LPSprimed TM, cleaved IL-1 $\beta$ was detected in the supernatants after UPEC infection with or without PK2 treatment, but the presence of cleaved IL-1 $\beta$ in the supernatants was eliminated by the inhibitors (Figure 5B, Supplementary Figures S10-S12).
Cleaved caspase-1 activity was stimulated by UPEC with or without PK2, but this activation was substantially depressed by MCC950, and VX-765 (Figure 5C). After the intervention with inhibitors, cleaved caspase-1 was not observed in the supernatants after UPEC infection with or without PK2 (Figure 5D, Supplementary Figures S4, S13, S14). Collectively, these data further confirmed that the NLRP3 inflammasome pathway is involved in PK2-mediated IL-1 $\beta$ secretion in TM.

\section{IL-1 $\beta$ Inhibits Testosterone Production by Suppressing P450scc and P450c17 Expression}

TM are structurally coupled with androgen-producing Leydig cells in the testicular interstitial space to constitute an immuneendocrine compartment. To determine whether IL-1 $\beta$ directly affects Leydig cells steroidogenesis, primary Leydig cells were treated with various concentrations of IL- $1 \beta$ ( $1 \mathrm{nM}, 10 \mathrm{nM}$, and $100 \mathrm{nM}$ ). The results revealed that, indeed, IL-1 $\beta$ directly inhibited testosterone biosynthesis in a dose-dependent manner (Figure 6A). Given that IL-1 $\beta$ has a pronounced influence on testosterone production, we hypothesized that the IL$1 \beta$ secretion from TM challenged with UPEC may inhibit testosterone synthesis. The supernatants of the LPS-primed TM after UPEC infection with or without PK2 were cocultured with primary Leydig cells. Testosterone production was shown to be decreased in Leydig cells after they were cocultured with TM supernatants. This hypothesis was further supported by using an anti-IL-1 $\beta$ antibody to neutralize IL-1 $\beta$, 

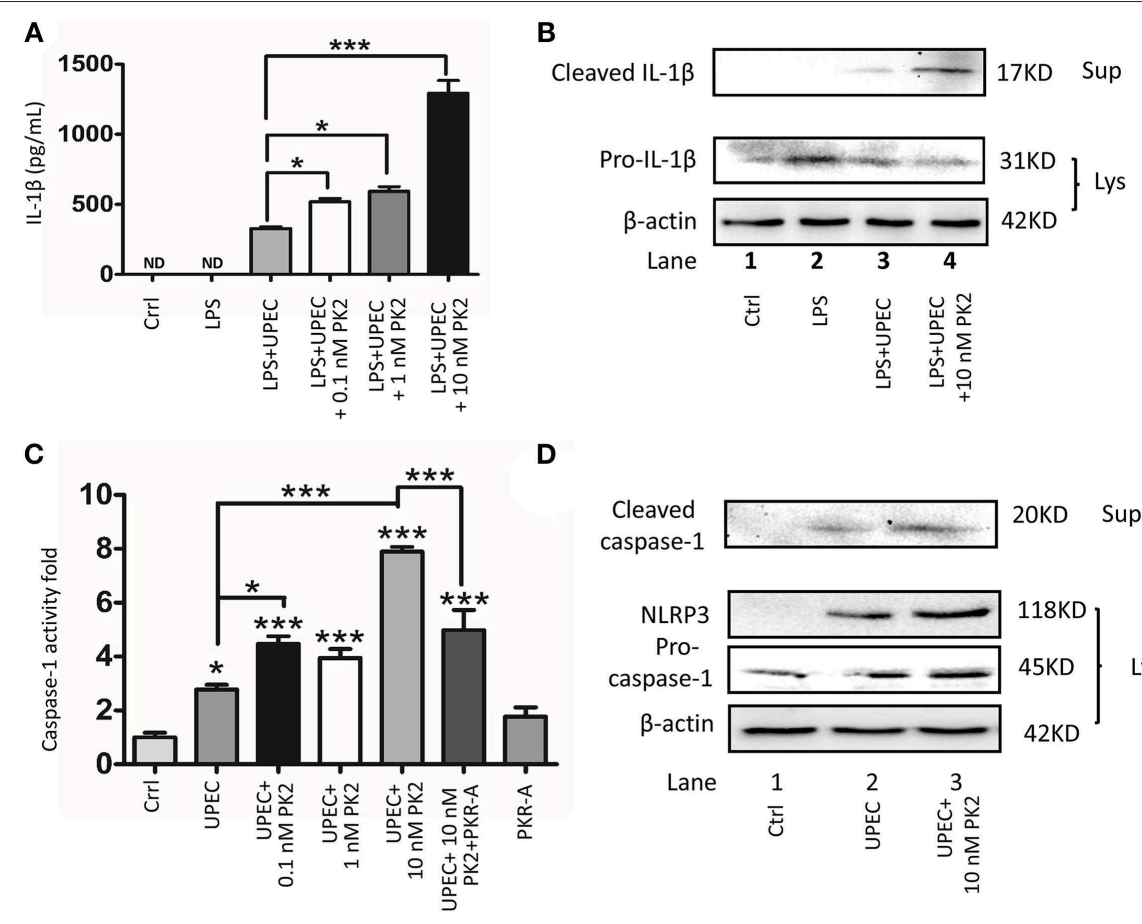

D

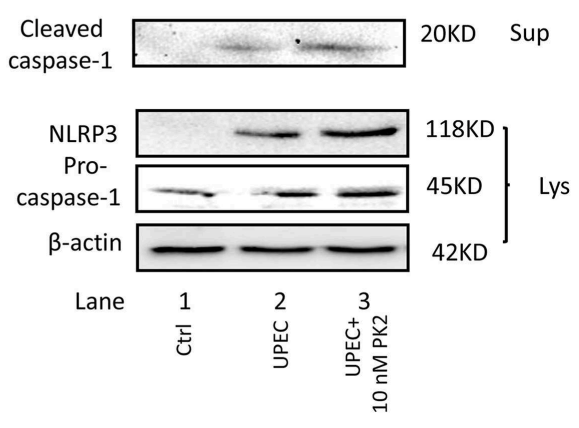

FIGURE 4 | PK2 promotes the NLRP3 pathway. (A) TM were primed with $1 \mu \mathrm{g} / \mathrm{mL}$ LPS for $4 \mathrm{~h}$ and then infected with UPEC (MOI 20) with or without various concentrations of PK2 $(0.1 \mathrm{nM}, 1 \mathrm{nM}$, and $10 \mathrm{nM})$ for $2 \mathrm{~h}$. IL-1 $\beta$ secretion in the supernatants was analyzed by ELISA. (B) TM and the supernatants were treated as described above. Whole-cell lysates and concentrated supernatants were analyzed by western blot with against IL-1 $\beta$ and $\beta$-actin. (C) TM were infected with UPEC $(\mathrm{MOI}=20)$ with or without PK2 for $2 \mathrm{~h}$. Whole-cell lysates were analyzed by caspase-1 activity assay. (D) TM were treated as described above. Whole-cell lysates were analyzed by western blot with antibodies against caspase-1 and concentrated supernatants were analyzed by western blot with antibodies against caspase-1, NLRP3, and $\beta$-actin. Ctrl, control; LPS, lipopolysaccharide; ND, no detected; Lys, cell lysates, Sup, supernatants. ${ }^{\star} P<0.05$, ${ }^{\star \star \star} P<0.001$ (one-way ANOVA).

which resulted in a marked increase in testosterone synthesis (Figure 6B). The results of LC-MS indicated that testosterone can be detected in the control group, however, the content of testosterone in the supernatants of some treatment groups (100 nM IL-1 $\beta$, LPS+UPEC, LPS+UPEC+10 nM PK2) is lower than the limit of detection, the corresponding results are not shown (Figure 6C). To explore the mechanism underlying the IL-1 $\beta$-induced inhibition of testosterone production, the mRNA expression of enzymes that are crucial for testosterone synthesis was detected in Leydig cells stimulated with IL$1 \beta$ in various concentrations. The results showed that the mRNA expression of steroidogenic acute regulatory protein (StAR) was increased, whereas cholesterol side-chain cleavage $\mathrm{P} 450$ (P450scc), and $17 \alpha$-hydroxylase/ $\mathrm{C}_{17-20}$ lyase (P450c17) were decreased, and no significant differences were found in the expression of $3 \beta$-hydroxysteroid dehydrogenase- $\Delta^{4}-\Delta^{5}$ isomerase ( $3 \beta$-HSD) or $17 \beta$-hydroxysteroid dehydrogenase $(17 \beta$ HSD) (Figure 6D). Then, the expression of genes encoding for key enzyme were detected in Leydig cells that were co-cultured with various supernatants. The results closely resembled those of the IL-1 $\beta$ treatment; upregulation of StAR and downregulation of P450scc and P450c17 were observed. These alterations were repressed by the anti-IL-1 $\beta$ antibody (Figure 6E). Taken together, these findings indicate that IL-1 $\beta$ secretion from TM exerts a negative effect on testosterone production by repressing the expression of $\mathrm{P} 450 \mathrm{scc}$ and $\mathrm{P} 450 \mathrm{c} 17$.

\section{DISCUSSION}

In this study, our results suggested that UPEC infection induces testicular inflammatory responses by promoting NLRP3 inflammasome activation in TM. Interestingly, the increased PK2 in TM and the testicular interstitial fluid augments this process. Moreover, IL-1 $\beta$ secretion from TM suppresses testosterone synthesis, which reduces the sperm count and forward motility. We reveal a novel mechanism of PK2 in regulating the NLRP3 inflammasome pathway to aggravate inflammatory damage and reduce testosterone production, which ultimately impairs male fertility.

There is growing evidence that increased PK2 levels in inflamed tissue is closely associated with the infiltration of inflammatory cells, thus PK2 may be a link between immune cells and the development of the inflammatory response (22, 23). In animal models of paw inflammation, the severity and duration of pain were related with the upregulation of PK2 expression in granulocytes (13). The relationship between PK2 and pathogen infection has also received considerable attention. LPS and bacterial DNA directly stimulated the upregulation 
A A

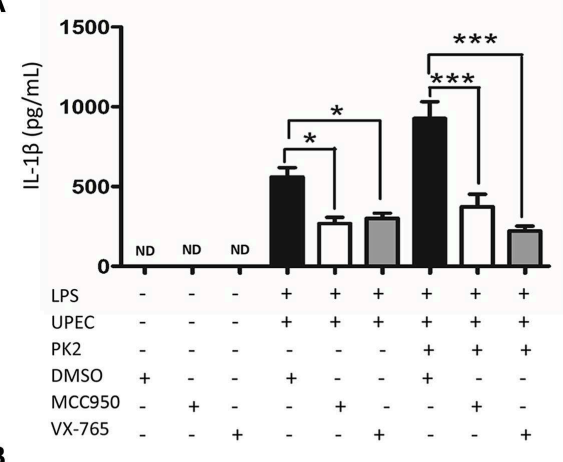

Cleave

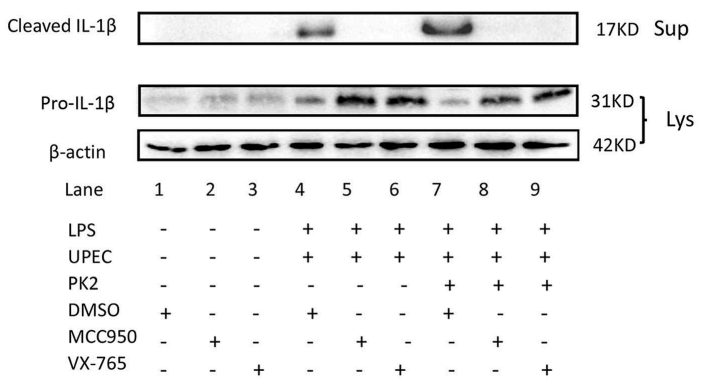

C
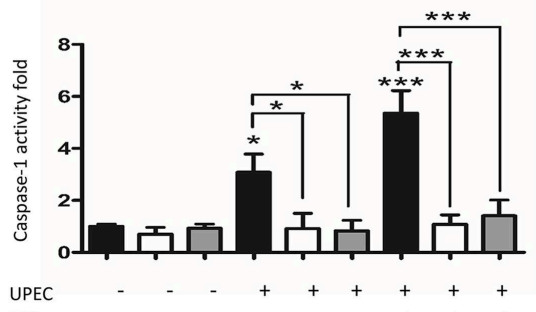

PK2 - - $\quad-\quad-\quad-\quad-\quad-\quad+\quad+\quad+$

DMSO $+-++-\quad+\quad+-$

$\begin{array}{llllllllll}M C C 950 & - & + & - & - & + & - & - & + & -\end{array}$

D

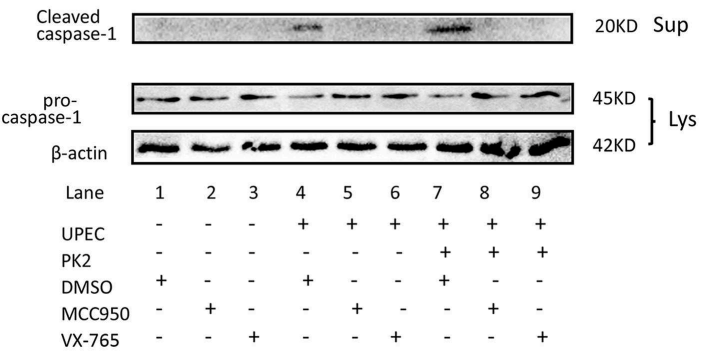

FIGURE 5 | The UPEC-mediated NLRP3 inflammasome activation is suppressed by NLRP3 and caspase-1 inhibition. (A) TM were primed with $1 \mu \mathrm{g} / \mathrm{mL}$ LPS for $4 \mathrm{~h}$ or left untreated, pretreated for $1 \mathrm{~h}$ with the NLRP3 inhibitor $(10 \mu \mathrm{M})$ or caspase- 1 inhibitor $(50 \mu \mathrm{M})$, and subsequently infected with UPEC (MOI = 20) with or without $10 \mathrm{nM}$ PK2 for $2 \mathrm{~h}$. The supernatants were collected at $2 \mathrm{~h}$ post-infection and analyzed for IL-1 $\beta$ release using ELISA. (B) TM were treated as described above, cell lysates as well as the supernatants were analyzed by western blot for IL-1 $\beta$, and $\beta$-actin. (C) TM were pretreated for $1 \mathrm{~h}$ with the NLRP3 inhibitor (10 $\mu \mathrm{M})$ or caspase-1 inhibitor $(50 \mu \mathrm{M})$ and subsequently infected with UPEC (MOI = 20) with or without $10 \mathrm{nM}$ PK2 for $2 \mathrm{~h}$. Whole-cell lysates were analyzed by caspase-1 activity assay. (D) TM were treated as described above. Whole-cell lysates and concentrated supernatants were analyzed by western blot with antibodies against caspase $1, \beta$-actin. Ctrl, control; LPS, lipopolysaccharide; DMSO, dimethylsulfoxide; ND, no detected; Lys, cell lysates, Sup, supernatants. ${ }^{\star} P<0.05$, ${ }^{\star \star \star} P<0.001$ (one-way ANOVA).

of PK2 in Raw 264.7 cells in vitro (14). Our findings were consistent with previous findings, as the upregulation of PK2 mRNA and protein was detected in TM isolated from the UPECinfected rats. Moreover, the supernatants of TM stimulated with UPEC and the testicular interstitial fluid exhibited the increased PK2 level. Overall, we inferred that the direct stimulation of invasive UPEC in the testicular interstitium induced the increased PK2 level. Furthermore, previous studies revealed that the PK2 signaling pathway involves both autocrine and paracrine loops to participate in multiple biological processes, such as the differentiation of cardiac and renal cells (24) and tumor angiogenesis (20). Given that the upregulation of the PK2 protein in the TM cytoplasm and the extracellular milieu, we inferred that UPEC not only upregulated PK2 transcription but also promoted the release of the functional PK2 protein from the TM to the testicular interstitium to further promote PK2 production.

Innate immune responses to pathogens are related with the assembly of large protein complexes defined as inflammasomes, and the functional component of this process is the release of the pro-inflammatory cytokine IL-1 $\beta$ (25). Zika-induced IL$1 \beta$ release was observed in human PBMCs and mouse bone marrow dendritic cells via the combining of the NS5 protein with NLRP3 (26). The bacterium Acinetobacter baumannii induced IL- $1 \beta$ secretion via the NLRP3-ASC-caspase-1 pathway, resulting in lung damage (27). Although the inflammation-related upregulation of IL-1 $\beta$ was previously observed in UPEC-infected TM, whether the NLRP3 inflammasome has any role in the pathogenesis was unknown. As the priming signal for IL-1 $\beta$ secretion, pro-IL-1 $\beta$ should be synthesized, which is thought to be primarily regulated in an NF- $\kappa \mathrm{B}$-dependent manner. However, recent studies have reported that the inflammasome is activated independent of NF-кB (28). Moreover, MAPK but not the NF- $\kappa \mathrm{B}$ pathway was activated in TM challenged with $\operatorname{UPEC}(5,6)$.

A second sequential signal, further stimulation, such as bacteria, triggers the NLRP3-ASC-caspase-1 assembly. In this study for the first time, we systematically demonstrated a significant increase in IL- $1 \beta$ release and cleaved caspase- 1 production in UPEC-infected rat TM. NLRP3 expression was identified to be a critical hallmark for NLRP3 activation (29), and the upregulation of the NLRP3 protein was also observed in TM isolated from UPEC-infected rats compared with the uninfected group in our study. Furthermore, TM were pretreated with LPS to acquire the priming signal in vitro as previously mentioned (21), and further stimulation with UPEC remarkably induced the production of the NLRP3, cleaved caspase-1, and cleaved IL-1 $\beta$ proteins. Moreover, the NLRP3 or caspase-1 inhibitors exerted clear inhibitory effects on the release of IL-1 $\beta$. Interestingly, LPS profoundly induced the synthesis of pro-IL-1 $\beta$ in TM, however, cleaved IL-1 $\beta$ could not be detected in the supernatants. LPS 


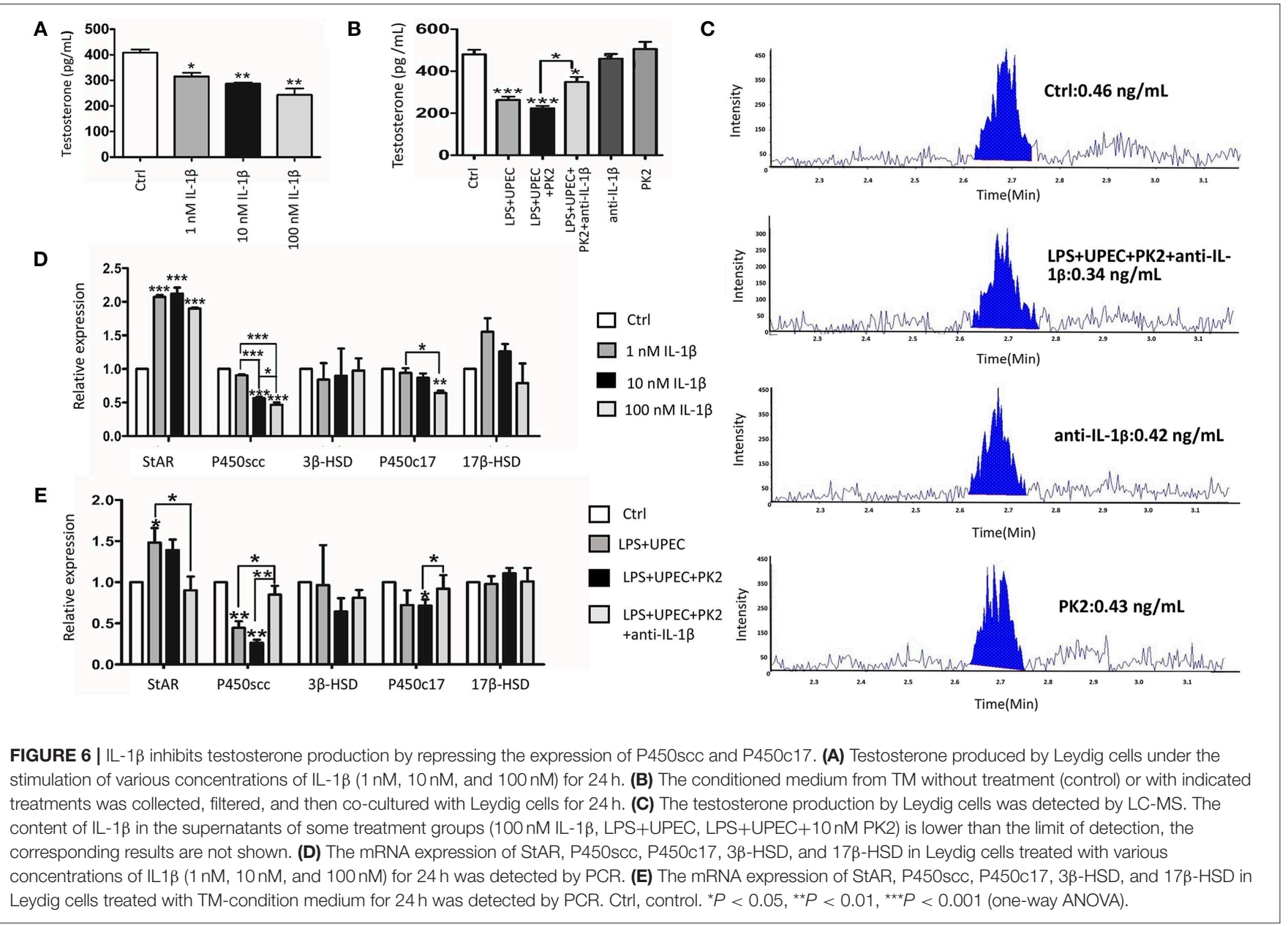

stimulated the TM to release pro-inflammatory cytokines, such as TNF- $\alpha$, at much lower levels compared to those in peritoneal macrophages (30), thus we inferred that the immunological characteristics of TM and the deficiency of inflammasome activation upon LPS stimulation may be attributed to the absence of IL- $1 \beta$.

IL-1 $\beta$ was not induced by PK2 in unstimulated cells, however, PK2 remarkably facilitates IL-1 $\beta$ release in LPSstimulated peritoneal macrophages (15). PK2 promotes the activation of the MAPK and AIM2 signaling pathways, and IL-1 $\beta$ secretion in THP-1 cells, however, systematic research on the underlying mechanism remains limited (14). In the UPEC-infected model, we demonstrated that PK2, and IL-1 $\beta$ expression were abnormally high in TM. To further investigate the relationship between these proteins, PK2 signaling inhibitor PKR-A was applied. In the animal model of stroke, when PK2 was delivered into the lateral ventricle post-stroke, $\mathrm{CD} 68^{+}$cells were significantly increased. (18). PKR-A was also administered in an animal model of collagen-induced arthritis (31) and autoimmune encephalomyelitis (32). In our UPEC-infected model, IL-1 $\beta$ secretion and caspase-1 cleavage were decreased after PKR-A treatment. Furthermore, in the western blot analysis, pro-IL$1 \beta$ was almost completely proteolytically cleaved to form the mature IL- $1 \beta$ in the UPEC-infected group, whereas pro-IL-1 $\beta$ was maintained in the PKR-A treated group, suggesting that the inflammasome effect on pro-IL-1 $\beta$ cleavage was repressed by PKR-A. Then, PK2 was added to TM-conditioned medium to verify the effect of PK2 on the inflammasome activation. PK2 significantly increased the expression of NLRP3, cleaved caspase1 and cleaved IL- $1 \beta$ after the UPEC infection, and this activation was suppressed by MCC950, and VX-765. This is the first report that PK2 plays a critical role in triggering the release of IL- $1 \beta$ in TM through the NLRP3 inflammasome pathway.

The testicular interstitium, an immune-endocrine compartment, contains a significant proportion of macrophages that are structurally coupled with Leydig cells (33). Several investigations suggested that activated macrophages induce the release of pro-inflammatory cytokines, such as IL-1 $\beta$, which profoundly repress the expression of genes encoding for steroidogenic enzymes in Leydig cells (34). IL-1 $\beta$ is not detected under normal physiological condition, and the absence of IL-1R has no effect on testosterone synthesis; IL-1R is required for IL-1-induced signal transduction in mice (35). In our study, primary Leydig cells were isolated and then cultured with various concentrations of IL-1 $\beta$. The results revealed that testosterone levels, P450scc and P450c17 synthesis were reduced, which 


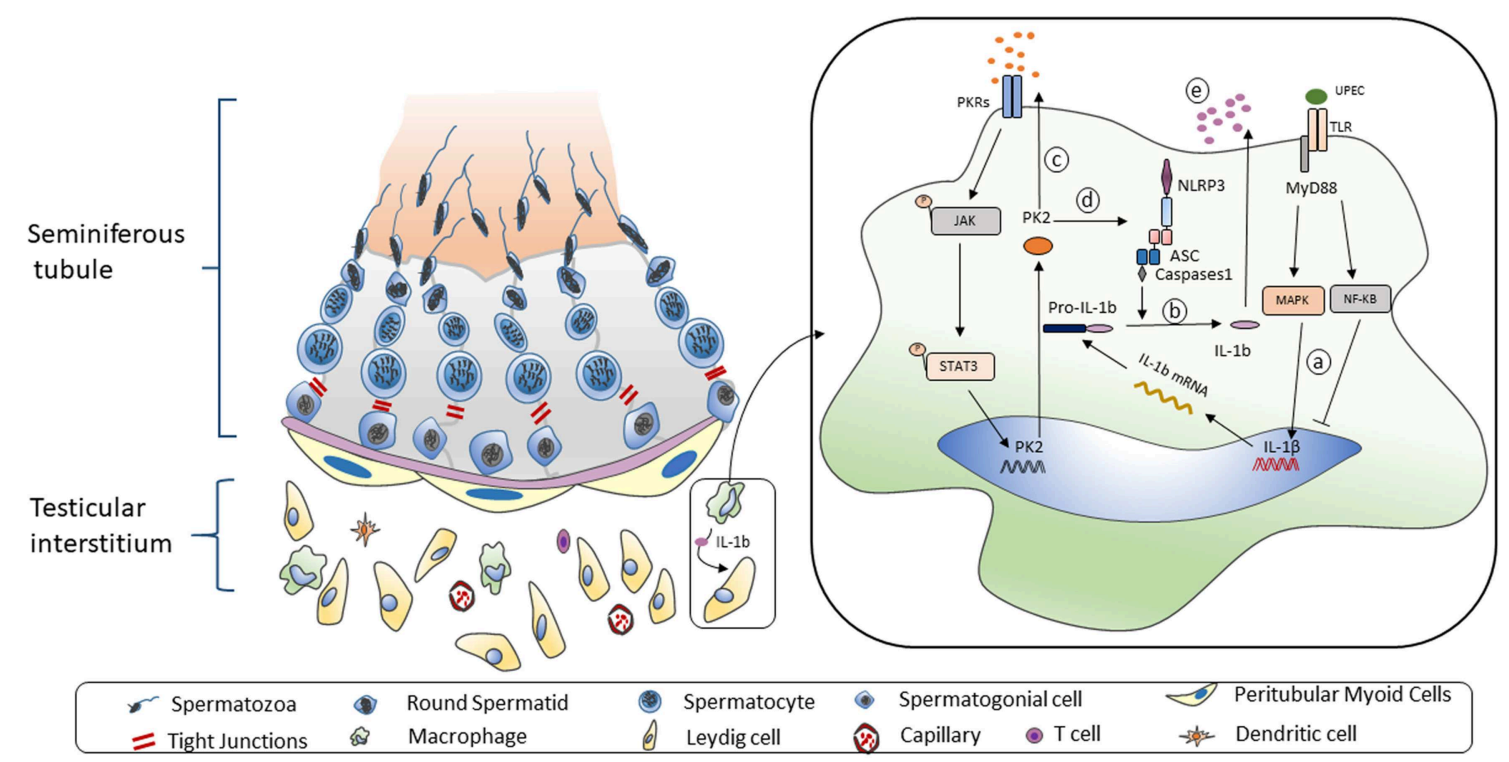

FIGURE 7 | Working model of UPEC-induced NLRP3 inflammasome activation in TM. Left: The mammalian testis is compartmentalized to two main parts. The seminiferous tubes are composed of various developing germ cells surrounded by Sertoli cells, while the testicular interstitial space consists of androgen-producing Leydig cells, and multiple types of immune cells. A significant proportion of macrophages is structurally coupled with Leydig cells with anatomical and functional relation. Right: When TM challenged by UPEC a. Activation of MAPK pathway but not NF-kB pathway induces the pro-IL- $1 \beta$ synthesis. b. The NLRP3 inflammasome pathway is triggered to secret IL-1 $\beta$. c. Biological function of TM-derived PK2 is augmented and sustained via an autocrine and paracrine manner. d. PK2 promotes

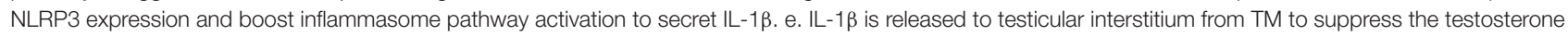
synthesis.

was consistent with previous data (36), however, the mRNA expression of StAR was shown to be increased in our study. The steroidogenesis process in Leydig cells includes the following two principal activities: the first step is an acute cAMP-dependent process requiring the action of the StAR. The second step is a chronic and durable stimulation, which involves the gene expression of the steroidogenic enzymes: P450scc, 3 $\beta$-HSD, P450c17, and $17 \beta$-HSD (37). We inferred that IL-1 $\beta$ triggers an acute compensatory response of testosterone synthesis via the upregulation of StAR, and then testosterone production is repressed by inhibiting $\mathrm{P} 450 \mathrm{scc}$, and $\mathrm{P} 450 \mathrm{c} 17$ in a chronic and durable process. TM-conditioned medium was co-cultured with Leydig cells to investigate the regulatory mechanism of immune-endocrine interactions (38). The conditioned medium collected from TM with various treatments was cocultured with primary Leydig cells in our research. The results were consistent with previous experiments involving IL-1 $\beta$ intervention, and the suppressive effect was abolished with an anti-IL-1 $\beta$ neutralizing antibody, which further supported our hypothesis.

In our research, the administration of PKR-A relieved the inflammatory damage to seminiferous epithelium cells and reduced the portion of inflammatory-activated state macrophages. Our results also suggested that after PKR-A treatment, the inflammation-induced testosterone reduction was attenuated, leading to an increase in the total sperm count and forward motility. Overall, PK2 plays important roles in the pro-inflammatory process of UPEC-induced orchitis by promoting IL-1 $\beta$ secretion in TM. A novel mechanism through which PK2 induces the NLRP3 inflammasome activation to boost IL-1 $\beta$ maturation after UPEC infection is presented here. The IL- $1 \beta$ is released from TM to the testicular interstitium where it affects adjacent Leydig cells and inhibits testosterone synthesis, leading to the impairment of spermatogenesis and, ultimately, male infertility (Figure 7). Our study enriches the knowledge regarding the role of PK2 in inflammatory diseases and provides a new viewpoint on the mechanisms underlying inflammation-associated male infertility. Moreover, these data suggest that PK2 is a potential immunomodulatory biomarker for orchitis and a novel anti-inflammatory therapeutic target for treating male infertility.

\section{DATA AVAILABILITY}

All datasets generated for this study are included in the manuscript and/or the Supplementary Files.

\section{ETHICS STATEMENT}

This study was performed in strict accordance with the approved guidelines from the Institutional Animal Care and Use Committee of Tongji Medical College, Huazhong University of Science and Technology. 


\section{AUTHOR CONTRIBUTIONS}

YL and KZ designed research studies, conducted experiments, analyzed data, and drafted the manuscript. YS conducted rat model establishment, cell isolation, and propagation of bacteria. TZ assisted in western blot and immunofluorescence of PK2 detection. $\mathrm{HZ}$ conducted animal execution and semen analysis. JW and WW conducted collection of testicular interstitial fluid and propagation of bacteria. $\mathrm{CL}$ and $\mathrm{ZH}$ provided intellectual input into planning of experiments and contributed to the writing of the manuscript.

\section{REFERENCES}

1. Virtanen HE, Jorgensen N, Toppari J. Semen quality in the 21(st) century. Nat Rev Urol. (2017) 14:120-30. doi: 10.1038/nrurol.2016.261

2. Wiles TJ, Kulesus RR, Mulvey MA. Origins and virulence mechanisms of uropathogenic Escherichia coli. Experim Mol Pathol. (2008) 85:11-9. doi: 10.1016/j.yexmp.2008.03.007

3. Vazquez-Levin $\mathrm{MH}$, Marin-Briggiler CI, Veaute C. Antisperm antibodies: invaluable tools toward the identification of sperm proteins involved in fertilization. Am J Reproduct Immunol. (2014) 72:206-18. doi: 10.1111/aji.12272

4. Wang M, Fijak M, Hossain H, Markmann M, Nusing RM, Lochnit G. et al. Characterization of the micro-environment of the testis that shapes the phenotype and function of testicular macrophages. J Immunol. (2017) 198:4327-40. doi: 10.4049/jimmunol.1700162

5. Bhushan S, Tchatalbachev S, Klug J, Fijak M, Pineau C, Chakraborty T. et al. Uropathogenic Escherichia coli block MyD88-dependent and activate MyD88independent signaling pathways in rat testicular cells. J Immunol. (2008) 180:5537-47. doi: 10.4049/jimmunol.180.8.5537

6. Bhushan S, Hossain H, Lu Y, Geisler A, Tchatalbachev S, Mikulski Z. et al. Uropathogenic E. coli induce different immune response in testicular and peritoneal macrophages: implications for testicular immune privilege. PloS ONE. (2011) 6:e28452. doi: 10.1371/journal.pone.0028452

7. Guazzone VA, Jacobo P, Theas MS, Lustig L. Cytokines and chemokines in testicular inflammation: A brief review. Microscopy Res Tech. (2009) 72:620-8. doi: 10.1002/jemt.20704

8. Marim FM, Franco MMC, Gomes MTR, Miraglia MC, Giambartolomei GH, Oliveira SC. The role of NLRP3 and AIM2 in inflammasome activation during Brucella abortus infection. Sem Immunopathol. (2017) 39:215-23. doi: 10.1007/s00281-016-0581-1

9. He Y, Hara H, Nunez G. Mechanism and regulation of NLRP3 inflammasome activation. Trends Biochem Sci. (2016) 41:1012-21. doi: 10.1016/j.tibs.2016.09.002

10. Hayrabedyan S, Todorova K, Jabeen A, Metodieva G, Toshkov S, Metodiev MV. et al. Sertoli cells have a functional NALP3 inflammasome that can modulate autophagy and cytokine production. Sci Rep. (2016) 6:18896. doi: $10.1038 /$ srep 18896

11. Walenta L, Schmid N, Schwarzer JU, Kohn FM, Urbanski HF, Behr R. et al. NLRP3 in somatic non-immune cells of rodent and primate testes. Reproduction. (2018) 156:231-8. doi: 10.1530/REP18-0111

12. Negri L, Ferrara N. The prokineticins: neuromodulators and mediators of inflammation and myeloid cell-dependent angiogenesis. Physiol Rev. (2018) 98:1055-82. doi: 10.1152/physrev.00012.2017

13. Giannini E, Lattanzi R, Nicotra A, Campese AF, Grazioli P, Screpanti I. et al. The chemokine Bv8/prokineticin 2 is up-regulated in inflammatory granulocytes and modulates inflammatory pain. Proc Natl Acad Sci USA. (2009) 106:14646-51. doi: 10.1073/pnas.0903720106

14. He X, Shen C, Lu Q, Li J, Wei Y, He L. et al. Prokineticin 2 plays a pivotal role in psoriasis. EBioMedicine. (2016) 13:248-61. doi: 10.1016/j.ebiom.2016.10.022

\section{ACKNOWLEDGMENTS}

This work was supported by the National Natural Science Foundation of China (Grant Nos. 81871148, 81701539, and 81571496). We thank Professor Qunyong Zhou for donating the anti-PK2 antibody for western blot and PKA-R.

\section{SUPPLEMENTARY MATERIAL}

The Supplementary Material for this article can be found online at: https://www.frontiersin.org/articles/10.3389/fimmu. 2019.01872/full\#supplementary-material

15. Martucci C, Franchi S, Giannini E, Tian H, Melchiorri P, Negri L. et al. Bv8, the amphibian homologue of the mammalian prokineticins, induces a proinflammatory phenotype of mouse macrophages. Br J Pharmacol. (2006) 147:225-34. doi: 10.1038/sj.bjp.0706467

16. Welch RA, Burland V, Plunkett G 3rd, Redford P, Roesch P, Rasko D. et al. Extensive mosaic structure revealed by the complete genome sequence of uropathogenic Escherichia coli. Proc Natl Acad Sci USA. (2002) 99:17020-4. doi: 10.1073/pnas.252529799

17. Lu Y, Bhushan S, Tchatalbachev S, Marconi M, Bergmann M, Weidner W. et al. Necrosis is the dominant cell death pathway in uropathogenic Escherichia coli elicited epididymo-orchitis and is responsible for damage of rat testis. PloS ONE. (2013) 8:e52919. doi: 10.1371/journal.pone.0052919

18. WHO. WHO Laboratory Manual for the Examination and Processing of Human Semen. 5th ed. Geneva: World Health Organization (2010).

19. Wang Y, Huang S, Wang Z, Chen F, Chen P, Zhao X. et al. Long-term maintenance of luteinizing hormone-responsive testosterone formation by primary rat Leydig cells in vitro. Mol Cell Endocrinol. (2018) 476:48-56. doi: 10.1016/j.mce.2018.04.008

20. Xin H, Lu R, Lee H, Zhang W, Zhang C, Deng J. et al. G-protein-coupled receptor agonist BV8/prokineticin-2 and STAT3 protein form a feed-forward loop in both normal and malignant myeloid cells. J Biol Chem. (2013) 288:13842-9. doi: 10.1074/jbc.M113.450049

21. Schaale K, Peters KM, Murthy AM, Fritzsche AK, Phan MD, Totsika M. et al. Strain- and host species-specific inflammasome activation, IL-1beta release, and cell death in macrophages infected with uropathogenic Escherichia coli. Mucosal Immunol. (2016) 9:124-36. doi: 10.1038/mi.2015.44

22. Negri L, Lattanzi R, Giannini E, Melchiorri P. Modulators of pain: Bv8 and prokineticins. Curr Neuropharmacol. (2006) 4:207-15. doi: 10.2174/157015906778019518

23. Lauttia S, Sihto H, Kavola H, Koljonen V, Bohling T, Joensuu H. Prokineticins and merkel cell polyomavirus infection in merkel cell carcinoma. Br J Cancer. (2014) 110:1446-55. doi: 10.1038/bjc.2014.20

24. Boulberdaa M, Urayama K, Nebigil CG. Prokineticin receptor 1 (PKR1) signalling in cardiovascular and kidney functions. Cardiovas Res. (2011) 92:191-8. doi: 10.1093/cvr/cvr228

25. Liston A, Masters SL. Homeostasis-altering molecular processes as mechanisms of inflammasome activation. Nat Rev Immunol. (2017) 17:208-14. doi: 10.1038/nri.2016.151

26. Wang W, Li G, De W, Luo Z, Pan P, Tian M. et al. Zika virus infection induces host inflammatory responses by facilitating NLRP3 inflammasome assembly and interleukin-1beta secretion. Nat Commun. (2018) 9:106. doi: 10.1038/s41467-017-02645-3

27. Dikshit N, Kale SD, Khameneh HJ, Balamuralidhar V, Tang CY, Kumar P. et al. NLRP3 inflammasome pathway has a critical role in the host immunity against clinically relevant Acinetobacter baumannii pulmonary infection. Mucosal Immunol. (2018) 11:257-72. doi: 10.1038/mi.2017.50

28. Demirel I, Persson A, Brauner A, Sarndahl E, Kruse R, Persson K. Activation of the NLRP3 inflammasome pathway by uropathogenic Escherichia coli is virulence factor-dependent and influences colonization of bladder epithelial cells. Front Cell Infect Microbiol. (2018) 8:81. doi: 10.3389/fcimb.2018.00081 
29. Bauernfeind FG, Horvath G, Stutz A, Alnemri ES, MacDonald K, Speert D. et al. Cutting edge: NF-kappaB activating pattern recognition and cytokine receptors license NLRP3 inflammasome activation by regulating NLRP3 expression. J Immunol. (2009) 183:787-91. doi: 10.4049/jimmunol.0901363

30. Bhushan S, Tchatalbachev S, Lu Y, Frohlich S, Fijak M, Vijayan V. et al. Differential activation of inflammatory pathways in testicular macrophages provides a rationale for their subdued inflammatory capacity. J Immunol. (2015) 194:5455-64. doi: 10.4049/jimmunol.1401132

31. Ito $\mathrm{H}$, Noda $\mathrm{K}$, Yoshida $\mathrm{K}$, Otani $\mathrm{K}$, Yoshiga $\mathrm{M}$, Oto $\mathrm{Y}$. et al. Prokineticin 2 antagonist, PKRA7 suppresses arthritis in mice with collagen-induced arthritis. BMC Musculoskeletal Disorders. (2016) 17:387. doi: 10.1186/s12891-016-1243-0

32. Abou-Hamdan $M$, Costanza $M$, Fontana E, Di Dario $M$, Musio S, Congiu C. et al. Critical role for prokineticin 2 in CNS autoimmunity. Neurol Neuroimmunol Neuroinflamm. (2015) 2:e95. doi: 10.1212/NXI.0000000000000095

33. Svingen T, Koopman P. Building the mammalian testis: origins, differentiation, and assembly of the component cell populations. Genes Develop. (2013) 27:2409-26. doi: 10.1101/gad.228080.113

34. Bornstein SR, Rutkowski H, Vrezas I. Cytokines and steroidogenesis. Mol Cell Endocrinol. (2004) 215:135-41. doi: 10.1016/j.mce.2003.11.022

35. Cohen PE, Pollard JW. Normal sexual function in male mice lacking a functional type I interleukin-1 (IL-1) receptor. Endocrinology. (1998) 139:8158. doi: $10.1210 /$ endo.139.2.5914
36. Zhang J, Li K, Yuan M, Zhang J, Huang G, Ao J, et al. A highfat diet impairs reproduction by decreasing the ILlbeta level in mice treated at immature stage. Sci Rep. (2017) 7:567. doi: 10.1038/s41598-01700505-0

37. Hales DB. Testicular macrophage modulation of Leydig cell steroidogenesis. $J$ Reproduct Immunol. (2002) 57:3-18. doi: 10.1016/S0165-0378(02) 00020-7

38. Dubey N, Lal B. Paracrine role of macrophage produced-nitric oxide (NO) in Leydig cell steroidogenesis in a teleost, clarias batrachus: impact of gonadotropin, growth hormone and insulin on no production by testicular macrophages. General Comparat Endocrinol. (2009) 160:12-8. doi: 10.1016/j.ygcen.2008.10.009

Conflict of Interest Statement: The authors declare that the research was conducted in the absence of any commercial or financial relationships that could be construed as a potential conflict of interest.

Copyright (c) $2019 \mathrm{Li}$, Su, Zhou, Hu, Wei, Wang, Liu, Zhang and Zhao. This is an open-access article distributed under the terms of the Creative Commons Attribution License (CC BY). The use, distribution or reproduction in other forums is permitted, provided the original author(s) and the copyright owner(s) are credited and that the original publication in this journal is cited, in accordance with accepted academic practice. No use, distribution or reproduction is permitted which does not comply with these terms. 